\title{
Longitudinal Study of Relapse From AIDS-Preventive Behavior Among Homosexual Men
}

\author{
Robin P. Graham, PhD, MPH \\ John P. Kirscht, $\mathrm{PhD}$ \\ Ronald C. Kessler, $\mathrm{PhD}$ \\ Saxon Graham, $\mathrm{PhD}$
}

\begin{abstract}
There is no viable alternative to the control of AIDS besides prevention; factors contributing to relapse from behaviors presumed to reduce risk of that disease were investigated. The authors studied 524 homosexual men who had refrained from or used condoms during receptive or insertive anal sex (RAS and IAS, respectively) for at least 12 months, contacting them at 6-month intervals thereafter to ascertain current practices. They determined, via interviews, personal traits, appraised stress of maintaining safer sex, mental health, life events, and efforts to cope with potential infection. Negative life events, personal control beliefs, problem-solving abilities, and coping via problem-focused (e.g., seeking a monogamous union) rather than emotion-focused (e.g., "when I need a cure, they will have one") behaviors were associated with RAS, but less so with IAS safer sex behaviors. These findings provide a basis for individual and community-level interventions to change behavior and reduce AIDS risk.
\end{abstract}

\section{INTRODUCTION}

The lack of any viable alternative emphasizes the public health need for preventing AIDS, and, although the behaviors required may appear simple, their introduction and maintenance in a population are complex. Much public health activity is directed to introducing and maintaining individual behaviors that can prevent disease, for example, quitting smoking, abstaining from substance abuse, and avoiding obesity. However, the level of success in such efforts often is not high, particularly in the long term, and additional basic research out of which to build intervention strategies remains vital.

This inquiry is a preliminary attempt to identify factors associated with relapse from behavior known to reduce risk of AIDS in homosexual men. Knowledge of such factors

Robin P. Graham, $\mathrm{PhD}, \mathrm{MPH}$, is a research assistant professor in the department of family medicine and social and preventive medicine at the State University of New York at Buffalo. John P. Kirscht, PhD, is a professor in the department of health behavior, School of Public Health, University of Michigan. Ronald C. $\mathrm{Kessler,} \mathrm{PhD}$, is a professor in the department of health care policy, Harvard Medical School. Saxon Graham, $\mathrm{PhD}$, is a professor emeritus in the department of social and preventive medicine, State University of New York at Buffalo.

Address reprint requests to Robin $\mathrm{P}$. Graham, $\mathrm{PhD}, \mathrm{MPH}$, State University of New York at Buffalo, Departments of Family Medicine and Social and Preventive Medicine, 462 Grider Street, Buffalo, NY 14215; phone: 716-898-5273; fax: 716-898-3536; e-mail: rgraham@ubmede.buffalo.edu

We dedicate this article to the memory of Professor John P. Kirscht. 
could provide a basis for programs for preventive intervention. The behaviors concerning us, receptive and insertive anal sex (RAS and IAS), are central to transmission of Human Immunodeficiency Virus (HIV), the infectious agent in the etiology of Acquired Immunodeficiency Syndrome (AIDS). While the proportion of AIDS cases among men who have sex with men decreased from $64 \%$ to $45 \%$ between 1981 and 1995 , this population continues to contribute the largest percentage of cases overall. ${ }^{1}$ Moreover, while there has been an impressive increase in the adoption of AIDS-preventive behaviors among homosexual men in large population centers of high AIDS incidence, reports from major investigations across multiple study sites in the past decade suggest that between $21 \%$ and $68 \%$ of homosexual men continue to engage in unprotected anal intercourse..$^{2-9}$

In addition, survey research has demonstrated that significant proportions of individuals who had adopted safer sex behaviors are not maintaining them over time; ${ }^{10-12}$ one investigator found that two-thirds of homosexual men engaging in high-risk sexual behaviors at one time point had relapsed from safer sex behaviors they initiated 5 years earlier. ${ }^{13}$ Other investigators of the maintenance of AIDS-preventive behaviors have found that from $13 \%$ to $65 \%$ of participants relapse over follow-up periods of variable length. ${ }^{5,6,14-18}$

Furthermore, while evaluation research findings indicate successes in intervention programs encouraging risk-reduction behaviors, relapse from safer to riskier sex at follow-up observation also is documented. ${ }^{19}$ Despite the need, a variety of methodological problems have limited investigation of relapse from AIDS-preventive behaviors. Students of relapse largely have failed to observe behavior over a lengthy period and to observe departures from maintenance of AIDS-preventive behavior over time. Longitudinal behavior change is often highly dynamic, involving repeated movement back and forth among states of relapse, recovery, and maintenance over many years. ${ }^{20-21}$

Past studies of maintenance of health-related behavior in general have considered durations of behavior of only 24 to 48 hours, and data gathering has been limited to 6 to 12 months postintervention, or even shorter periods, for example, 1 month. Hence, the validity of findings about relapse from established, longer term maintenance behavior is highly questionable. ${ }^{21-25}$ Moreover, samples typically are of individuals in therapeutic groups, which limits generalizability of findings. ${ }^{22,26}$

The prospective, multiwave panel design of our research enabled us to overcome some of the shortcomings in earlier investigations. Our study sample was composed of men who had maintained safer sex practices for 1 year at sample entry, and we followed them for 18 months thereafter. This allowed us to study a congeries of factors associated with long-term relapse from maintenance of AIDS-preventive behavior.

We should emphasize that the period during which our data were collected was 10 to 14 years ago. Nevertheless, the behaviors under investigation here remain of utmost importance to the prevention of AIDS. In fact, a recent reexamination of the HIV seroconversion literature asserts that "consistent" condom use, when measured uniquely vis-à-vis all condom use behavior, results in prevention of sexual transmission of HIV $90 \%$ to $95 \%$ of the time. This is in contrast to earlier meta-analytic study indicating $60 \%$ to $70 \%$ prophylactic success among all condom users. ${ }^{27}$ Again, this is in light of the high rates of inconsistent condom use across high-risk populations. ${ }^{8,18}$

Furthermore, increased study of these psychosocial phenomena (e.g., threat, appraisal, coping response) is vital to the explanation not only of AIDS-related behaviors but also of a great number and variety of other health-related behaviors and to design of theorydriven interventions. ${ }^{28-33}$ Moreover, there are few investigations exhibiting the methodological rigor of our 30-month multiwave study of predictors of behavioral patterns within a large panel of condom users. ${ }^{28}$ Overall, despite the age of our data, our findings are 
cogent because (1) consistency in condom use continues to be an effective preventive of AIDS and condom use too often is sporadic, and (2) the factors we discover allowing relapse from condom use are possibly associated with relapse from other types of preventive behaviors. ${ }^{30}$

\section{THEORETICAL AND EMPIRICAL FOUNDATIONS}

Explanatory research devoted to relapse overwhelmingly has emphasized physiological factors and environmental stimuli (e.g., social pressure, situational cues). Although a major, current theoretical paradigm for understanding relapse highlights the influence of coping response and primary and secondary appraisal, there remains meager empirical study of these concepts. ${ }^{34}$ Unfortunately, although some research has examined stressrelated situations and negative emotional determinants of relapse, study of the influence of cognitive appraisal of stress on relapse in given situations has not been addressed. ${ }^{35}$ Moreover, meager attention has been given to coping response and, in particular, to the identification of those dimensions of coping that may influence relapse ${ }^{36,37}$ In addition, investigators generally have restricted their specification of variables to either distal (e.g., mental health) or proximal (e.g., coping response) predictors of relapse. ${ }^{38}$ Finally, sociodemographics, background stress, immediate stresses, and mental health represent other potentially important factors that have been neglected. The third gap in our knowledge of factors influencing relapse arises from the fact that although numerous factors have been identified as being of importance, their joint effects rarely have been assessed. ${ }^{38}$ Equally important, studies of relapse from AIDS-preventive behaviors usually have neglected those determinants uniquely influencing specific individual behaviors. ${ }^{39}$

To address these deficiencies, we proposed a conceptual paradigm specifying personal factors (which may serve as coping resources), ${ }^{40}$ cognitive appraisal, coping response, mental health, and background stress (negative life events). Furthermore, we posited that these distal and proximal variables together would affect the dynamic pattern of individuals' maintenance or relapse from safer sex behaviors. Figure 1 displays variables (shown in the rectangles) that contribute to measurement of each construct (noted in the circles) in the current study.

Table 1 indicates the specific questions we asked and scales used to measure variables underlying constructs hypothesized to be relevant to relapse. Among the personal traits assessed were beliefs regarding the extent of control or helplessness one has, one's approach to problem solving, and one's skill in dealing with potential partners. Note that we queried on extent of control over one's life in general using Perlin's approach, as well as on control in specific situations as did Rosenbaum. Regarding appraisal, we asked the degree of stress or dissatisfaction one experienced in abstaining from anal sex or in using condoms. Coping deals with either abstinence or maintenance and takes two forms: emotion-focused, which consists primarily of rationalizations for continuing high-risk behavior (e.g., chance of getting AIDS increases enjoyment, by the time I need a cure there will be one, does not like to think about it), or problem-focused, for example, seeking a monogamous lover, using a douche or lubricant, and other concrete measures to avoid infection. Reactions to coping with AIDS included keeping a health-conscious regimen, being more religious, helping other homosexuals, and resorting to fatalism. Mental health comprises often-used measures of depression and anxiety and measures of more specific concerns about AIDS. Negative life events have to do with measures of experiences in 


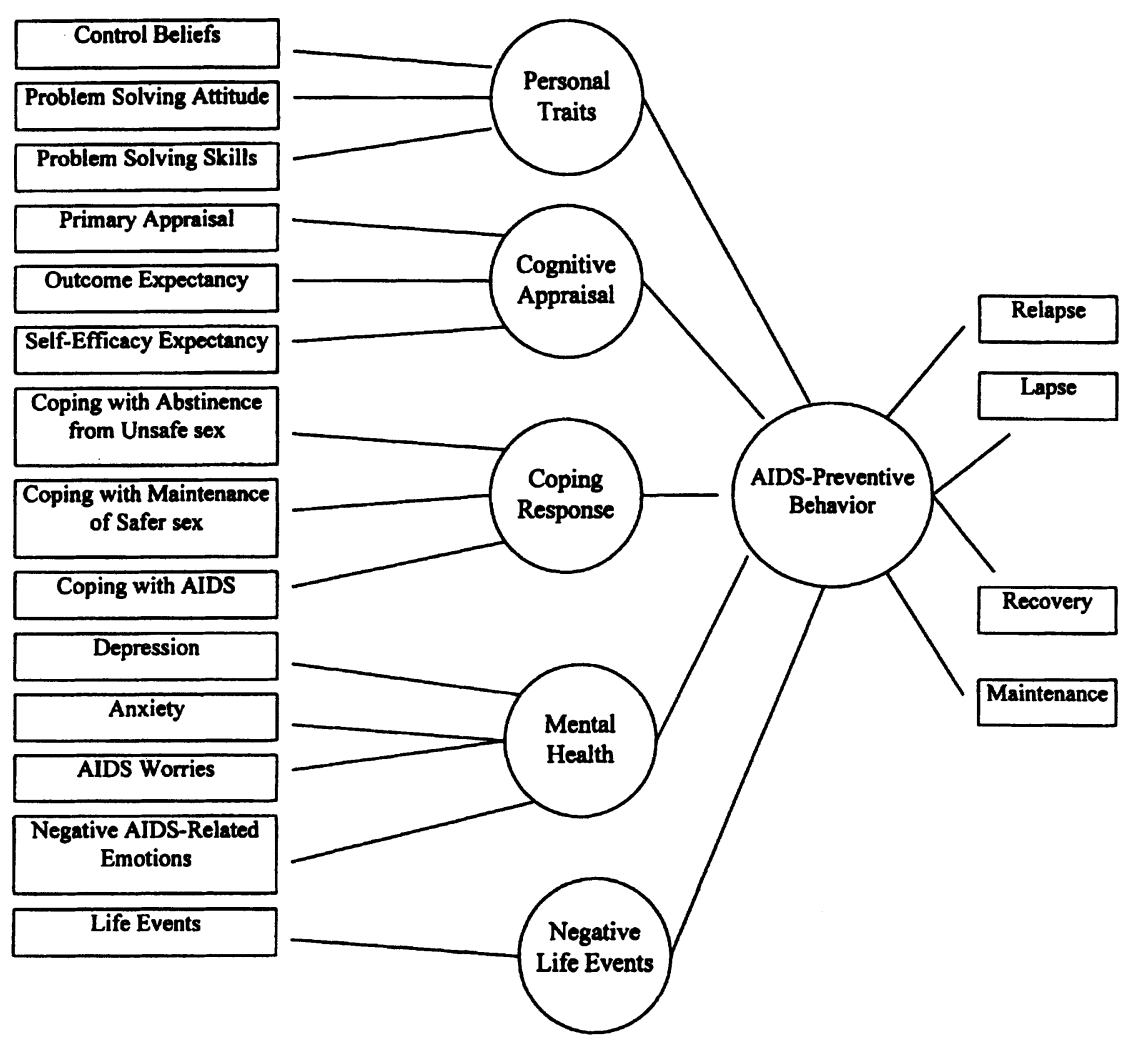

Figure 1. The Conceptual Model.

the variety of major life domains, including problems with work, money, law, love, friendship, and family relations, as well as "coming out." We hypothesized that these constructs would be associated with maintenance of or relapse from safer sex behaviors. The safer sex behaviors concerning us were (1) abstaining from anal sex or (2) using condoms during either IAS or RAS with all partners always. Further elaboration of the composition and construction of indices has been discussed elsewhere by Joseph and others, ${ }^{41,44}$ but as is often the case, these constructs could be associated with the outcomes in subtle ways. Our findings suggest that this indeed is the case, as shown by the coefficients displayed in Table 1 , to be discussed shortly.

\section{METHODOLOGY}

\section{Sampling}

The sample was drawn from 1,012 Chicago homosexual males participating in the Coping and Change Study (CCS) from 1984 to 1988. The CCS was designed to 
Table 1. Reliability and Coefficients of Variables Associated With Relapse or Maintenance of AIDS-Preventive Behavior for Receptive Anal Sex and Insertive Anal Sex

\begin{tabular}{lccc}
\hline Questions Asked to Measure Constructs & Reliability & $\begin{array}{c}\text { Receptive Sex } \\
\text { Coefficient }\end{array}$ & $\begin{array}{c}\text { Insertive Sex } \\
\text { Coefficient }\end{array}$ \\
\hline $\begin{array}{l}\text { Personal Traits: } \\
\text { Beliefs regarding control: Perlin Mastery Index, } \\
\text { seven items: has little control; is helpless; can't } \\
\text { change; is pushed around }\end{array}$ & .81 & 0.48 & -.40 \\
$\begin{array}{l}\text { Problem solving: has a systematic approach; } \\
\text { weighs alternatives }\end{array}$ & .41 & 1.01 & .81 \\
$\begin{array}{l}\text { Skill in dealing with potential partners: } \\
\text { Rosenbaum Index, three items: can't ask } \\
\text { about sex history of potential partner; can't } \\
\text { ask regarding AIDS; can't say no }\end{array}$ & & & \\
\end{tabular}

Appraisal:

Primary appraisal (three items): For those who have engaged in RAS or IAS, how stressful has it been in past month to:

Abstain from sex
Limit to RAS or IAS with condoms only
Do all the above on a daily basis to
prevent AIDS

Outcome expectancy (without condom): RAS or IAS without condom is unsatisfying, 4 levels

Outcome expectancy (with condom): How satisfying is RAS or IAS with condom? 4 levels

Self-efficacy expectancy: two items: Has trouble observing "safer sex"

$\begin{array}{lrc}\text { N/A } & -14.30 & \text { Not studied } \\ \text { N/A } & 2.26 & \text { Not studied } \\ & & \\ \text { N/A } & -1.22 & .65\end{array}$

Product

$\begin{array}{ccc}\text { moment } r=.52 & 1.42 & .11 \\ \text { Product } & & \\ \begin{array}{c}\text { moment } r=.58 \\ \quad \text { Product }\end{array} & 0.53 & -.54 \\ \text { moment } r=.32 & -4.68 & .14\end{array}$

\section{Coping response:}

Emotion-focused coping with abstinence:

five items: Is too lucky to get AIDS; chance of getting AIDS increases enjoyment; heterosexual researchers on AIDS are biased; too little is known regarding AIDS; if and when I need a cure, there will be one Coefficient theta $2.42 \quad$ Not studied Problem-focused coping with abstinence: four items: Ascertains whether partner is safe; uses douche, lubricant; asks partner to with draw before orgasm Emotion-focused coping with maintenance: three items: Don't like to think about it; being gay means doing what I want; would have to stop all sex ient theta range $=.47-.66$

Problem-focused coping with maintenance: two items: Be monogamous; find

Coefficient theta monogamous lover range $=.780-.781$ 
Table 1. Continued

\begin{tabular}{|c|c|c|c|}
\hline Questions Asked to Measure Constructs & Reliability & $\begin{array}{l}\text { Receptive Sex } \\
\text { Coefficient }\end{array}$ & $\begin{array}{l}\text { Insertive Sex } \\
\text { Coefficient }\end{array}$ \\
\hline In coping with AIDS: & \multicolumn{3}{|c|}{$\begin{array}{l}\text { Alpha reliability } \\
\text { coefficients: } \\
\text { range } \\
.63-.76\end{array}$} \\
\hline \multicolumn{4}{|l|}{$\begin{array}{l}\text { 1. Four items: Pays more attention to health; } \\
\text { sees doctor; keeps healthy, watches for } \\
\text { symptoms; other health problems }\end{array}$} \\
\hline $\begin{array}{l}\text { 2. Is fatalistic; refuses to think about it; if } \\
\text { you're going to get it, you'll get it }\end{array}$ & \multicolumn{2}{|c|}{ 2. Is fatalistic; refuses to think about it; if } & Not studied \\
\hline $\begin{array}{l}\text { 3. Seven items: Interacts more with gay } \\
\text { organizations, helps other gays }\end{array}$ & \multicolumn{2}{|c|}{ 3. Seven items: Interacts more with gay } & Not studied \\
\hline 4. Three items: Behaves more religiously & & 0.60 & Not studied \\
\hline \multicolumn{4}{|l|}{ Mental health: } \\
\hline Studies Scale & .79 & 0.53 & .53 \\
\hline \multicolumn{4}{|l|}{ 2. Anxiety: six items: Hopkins Anxiety } \\
\hline Symptoms Checklist & .81 & -0.19 & -.90 \\
\hline \multicolumn{4}{|l|}{ 3. Six items: Worried about AIDS } \\
\hline $\begin{array}{l}\text { 4. Six items: Worries regarding AIDS } \\
\text { interfered with life and relaxing, thinking, } \\
\text { friendships, job, sleep, sex }\end{array}$ & .78 & -0.31 & .38 \\
\hline \multicolumn{4}{|l|}{ Life events: Negative occurrences } \\
\hline \multicolumn{4}{|l|}{ 1. Work: demoted, fired, conflict, increased } \\
\hline \multicolumn{4}{|l|}{ 2. Finance: salary cut, no demotion; major } \\
\hline \multirow{2}{*}{$\begin{array}{l}\text { 3. Legal: went to jail; arrested; victim of robbery } \\
\text { 4. Love relations: fight with primary partner, ill, } \\
\text { relationship ended }\end{array}$} & N/A & 2.48 & 1.04 \\
\hline & N/A & 2.83 & .47 \\
\hline $\begin{array}{l}\text { 5. Family: death or illness of child, sibling, } \\
\text { parent; argument with family member }\end{array}$ & N/A & 5.33 & .81 \\
\hline \multirow{2}{*}{$\begin{array}{l}\text { 6. Friend: death, serious argument, illness of } \\
\text { close friend } \\
\text { 7. Coming out: to coworkers, relations, M.D., } \\
\text { hetero friends }\end{array}$} & N/A & 3.09 & -.64 \\
\hline & N/A & -7.38 & .41 \\
\hline
\end{tabular}

NOTE: - = Maintenance; + = Lapse; RAS = Receptive Anal Sex; IAS = Insertive Anal Sex

investigate behavioral and psychological aspects of the HIV epidemic, and it was a component of the Multicenter AIDS Cohort Study (MACS), an epidemiological investigation of the natural history of HIV among several panels of homosexual men across the United States. Because complete enumeration of the homosexual population is not feasible, the representativeness of the CCS sample is impossible to determine. However, as Table 2 shows, men enrolled in this study are sociodemographically and behaviorally 
Table 2. Descriptive Statistics for the Analytic Sample, 1984-1988

\begin{tabular}{ll}
\hline Variable & $(N=524)$ \\
\hline Mean age & 34.6 \\
White, non-Hispanic & $92.0 \%$ \\
Mean income & $\$ 23,640$ \\
Mean years education & 16.5 years \\
Religion: & \\
$\quad$ Jewish & $7.3 \%$ \\
Catholic & $25.1 \%$ \\
Protestant & $32.4 \%$ \\
HIV seropositivity (without AIDS) & $37.6 \%$ \\
Engages in RAS & $51 \%$ \\
Engages in IAS & $49 \%$ \\
Receptive lapsers and relapsers & $15.5 \%$ \\
Receptive maintainers & $36 \%$ \\
Insertive lapsers and relapsers & $12.2 \%$ \\
Insertive maintainers & $37 \%$ \\
\hline
\end{tabular}

NOTE: RAS = Receptive Anal Sex; IAS = Insertive Anal Sex

similar to other samples of homosexual men being studied elsewhere. ${ }^{41}$ The sample used in the present report was composed of panel members who abstained from RAS or IAS, or used condoms during RAS or IAS for 12 months prior to interview. MACS participants were interviewed in waves at 6-month intervals. Our participants had to have abstained from unprotected sex or used condoms for two consecutive 6-month waves to be eligible for sample inclusion. They were then observed for three waves (18 months) thereafter. Due to the possibility of response bias, our respondents, of whom $38 \%$ were HIV positive, became ineligible for sample inclusion if they developed AIDS at any point during the data collection.

Nonresponse rates from dropouts, $4.18 \%$, and questionnaire noncompletion, $13.1 \%$, were constant over time. Ongoing study of differential out-selection from the CCS sample over the four waves of the study has revealed no statistically significant differences between those lost and retained. Ultimately, we studied a group of 524 homosexual men found to have maintained safer sex behavior for at least two consecutive 6-month intervals. We continued to follow them for three 6-month intervals thereafter to ascertain whether they relapsed from such behaviors and to gather data regarding the constructs described above. ${ }^{42}$ An assessment of the sociodemographic and HIV serostatus comparability of the entire CCS sample and the present analytic one was conducted, and only very minor differences were noted. Further details regarding these and other aspects of methodology may be found in Joseph et al..$^{43,44}$

Individuals were placed in mutually exclusive strata based on their longitudinal behavior patterns over the three 6-month intervals as revealed in answers to the following questionnaire item: "For each type of sexual partner, i.e., primary or steady, know well but not steady, casual but not anonymous, or anonymous, about how often in the past month was a condom used when you were the receptive partner in anal sex?" The response options were as follows: always $=1$, sometimes $=2$, never $=3$, no partners $=8$. The same question was asked regarding IAS.

Mutually exclusive strata were formed from the answers as follows: stratum 1, relapse: for two or more sequential waves, the respondent scored 2 and/or 3; stratum 2, lapse: for 
one wave, the respondent scored 2 or 3 ; and stratum 3, maintenance: all waves scored 1 and/or 8. Thus, those who relapsed had abandoned safer sex behavior for two or more 6-month periods. Those who had lapsed (stratum 2) had abandoned safer sex behavior for one 6-month period. Maintainers had continued safe sex behavior or had no partners at all for all three 6-month periods. For stratums 1 and 2, regardless of the type of sexual partner, primary, casual, or anonymous, there is a high risk of exposure to AIDS. The analyses examined all four types of sexual partner together. The only behavior that comprises safe sex is maintenance, that is, stratum 3 . The analyses were carried out separately for IAS and RAS.

\section{Statistical Analyses}

In addition to analysis of factors relevant to our major hypothesis, background characteristics were examined, including age, education, income, and religion, as well as HIV serostatus, the time at which the individuals were selected to the analytic sample, and the percentage of maintenance and lapsers of various sorts (see Table 2). In an initial test of the original model, sociodemographic variables including age, race, income, education, and religion were determined to be insignificant in their contribution to overall explanatory power. For this reason and because sample sizes were reduced owing to missing demographic data, these variables were dropped from subsequent analyses.

Following descriptive analyses, multinomial logistic regression models with unordered variables were fit by the method of maximum likelihood..$^{45}$ Two types of statistical tests were undertaken. One, based on asymptotic $t$ tests, addressed the significance of individual model variables (see Table 1). The second set of tests was based on a likelihood ratio approach for testing nested hypotheses (see Table 3 ). ${ }^{46}$

\section{RESULTS}

\section{The Receptive Anal Sex Model}

To examine whether the factors we posited as being relevant to lapse or maintenance were indeed associated, we tested overall goodness of fit by first fitting a model that incorporated all individual variables noted in Table 1 . Here, $\mathrm{L}=-2(\log$ of the likelihood function). $\mathrm{L}$ for the full model was 247.27. A marginal model next was estimated that included only a constant variable, giving rise to $L>408.26$. The difference between these, the likelihood statistic, is 160.99 and is distributed as a chi-square variate. ${ }^{46}$ The $p$ value for this overall goodness-of-fit test statistic is .0002 . We conclude that, taken together, the congeries of variables we studied was associated with relapse.

We next studied submodels derived by sequential exclusion of our five exogenous constructs: personal traits, appraisal, coping response, mental health, and negative life events, as shown in Figure 1. Using the same likelihood ratio procedure as above, we inspected the contributions each of these constructs made to overall significance of the full model. A summary of the analysis of reduced models for RAS is found in Table 3. The test of the logit model excluding variables representing personal traits, coping response, negative life events, and coping with safer sex, each studied separately, showed that these were statistically important factors $(p<.005)$. 
Table 3. Likelihood Ratio Statistics for Full and Reduced Receptive and Insertive Anal Sex Models

\begin{tabular}{lll}
\hline & Receptive & Insertive \\
\hline Reduced/model & & \\
$\quad$ Personal traits & $48.96(3 d f)^{* *}$ & $10.54(3 d f)^{*}$ \\
Appraisal of behaviors & $17.85(7 d f)^{*}$ & $21.86(5 d f)^{* *}$ \\
Coping response & $64.29(8 d f)^{* *}$ & $20.55(6 d f)^{* *}$ \\
Mental health & $10.99(4 d f)^{*}$ & $21.76(4 d f)^{* *}$ \\
Negative life events & $45.63(7 d f)^{* *}$ & $32.82(7 d f)^{* *}$ \\
Coping with AIDS threat & $11.91(4 d f)^{*}$ & \\
Coping with safer sex: Abstinence or maintenance & $18.91(4 d f)^{* *}$ & \\
\hline
\end{tabular}

${ }^{*} p<.05 . * *<.005$.

or maintenance. Similarly, neither the cognitive appraisal construct nor the mental health variables showed a high degree of relationship. We conclude that a variety of coping response forms, personal traits, and life events were importantly associated with lapse from safer sex behaviors.

Other background characteristics, including HIV serostatus, wave at selection, total number of steady sexual partners, and total number of all other partners were considered constants for further tests. Their contribution varied across the strata, but findings are suggestive of their general lack of explanatory influence in discriminating among relapse, lapse, recovery, and maintenance behavior.

\section{Insertive Anal Sex}

Tests of overall goodness of fit began by fitting a full model composed of all the variables in Table 1. L for the full model was found to be 284.51; the marginal model, including only a constant variable, yielded $\mathrm{L}=396.48$, and the likelihood ratio statistic generated from a calculation of the difference of these estimates was 111.98. The $p$ value of this overall goodness-of-fit test statistic was .0582, suggesting that together the factors under investigation are not associated importantly with relapse, lapse, or maintenance. In general, $t$ tests on individual variables were not significant (see Graham, 1991, for more complete discussion). ${ }^{44}$

As a congeries, the indicators of appraisal behaviors, coping response, and mental health appear influential to the overall explanatory power of the initial fitted model (see Table 3). Negative life events had an even greater explanatory influence $(p<.005)$. Initial model testing again established the lack of significance of demographic factors, and, therefore, they were omitted from subsequent analyses because of missing data. As Table 1 shows, none of the individual variables composing the constructs uniquely contributed to relapse or maintenance of risk-reducing behavior for insertive sex.

\section{Individual Factors}




\section{Individual Factors}

Table 1 exhibits coefficients of relationships between individual variables composing the constructs discussed above and maintenance of or relapse from AIDS-preventive behavior. A negative coefficient indicated the factor to be associated with maintenance, while a positive one indicated an association with relapse. Although none of these $t$ test results was significant, perhaps because of small numbers, the variables generating large coefficients deserve comment and replication with larger numbers in future research. Moreover, they furnish clues as to public health approaches to fostering AIDS-preventive behaviors. For example, note that emotion-focused coping with maintenance, measured by positive answers to the statements, "I don't like to think about it," "being gay means doing what I want," and "if I try to require use of condoms, I'd have to give up all sex," indicating a fatalistic or denial-based rationalization for unsafe behaviors, carries the largest coefficient, 19.78, suggesting an association with relapse from maintenance of safe practices for RAS. Also regarding RAS, we discovered associations between relapse and certain negative life events, specifically, problems at work, with law, and with love, family, and friendship relations. On the other hand, "coming out" and money problems were associated with maintenance of safer sex behavior. Increases in the amount of stress associated with abstention from sex also were associated with maintenance (coefficient was-14.3). Similarly, those who found asking about the possibility of AIDS in a potential partner difficult and those who "can't say no" were more likely to maintain safer sex behavior. These findings appear to defy the logic shown in other relationships. However, they may suggest that such beliefs and attitudes are associated with maintenance of condom use in the absence of abstinence. Consistent with this, those lacking skill at other safer sex behaviors (e.g., asking about the possibility of AIDS in the partner) may more likely adopt condoms. All of these findings require replication with larger samples.

It is noteworthy that we have examined a fair number of factors and found a number not to be related to maintenance or relapse. Obviously, attitude toward a given behavior and the behavior itself are related but not necessarily in a cause-and-effect relationship. We have seen in Table 1 that a number of constructs and the variables composing them were not related in any important way to outcome behaviors. Thus, personal traits, satisfaction with the condom in RAS or IAS, all of the coping with AIDS factors, and the mental health factors are unrelated to relapse or maintenance behavior. Note that those dealing specifically with the kind of behavior we are studying, that is, the six items in the Mental Health scale concerning worries about AIDS and the items indicating that these interfere with relaxing, thinking, friendships, jobs, sleep, and sex, were not related to the actual behavior of attempting to prevent AIDS.

On the other hand, as we have seen, there is a considerable number of fairly strong relationships with relapse or maintenance in the case of such items as skill in dealing with potential partners and emotion-focused coping with maintenance. We emphasize that even these important relationships were not found to be statistically significant; nevertheless, they did stand out as being potentially far more strongly related than those aforementioned factors dealing with coping with AIDS and mental health.

\section{DISCUSSION}

This is a study of factors associated with relapse from and maintenance of AIDSpreventive behavior over a period of 18 months by 524 men who had practiced AIDS- 
preventive behavior for 12 months previously. Based on our elaboration of Marlatt and Gordon's model, ${ }^{39}$ we hypothesized that five constructs would be related to relapse or maintenance: (1) personal traits, such as approaches to problem solving and beliefs about amount of control one has over one's environment; (2) appraisal of the stress induced by adhering to risk-reduction behaviors (abstinence or using condoms in anal intercourse); (3) type of coping response; (4) mental health, as measured by a variety of well-tested devices; and (5) negative life events, at work and in family, legal, financial, love, and friend relationships.

Briefly, we found that, as noted in Table 1, emotion-focused coping with maintenance was associated with relapse in the case of RAS, as was problem-focused coping. Emotion-focused coping tends to ignore the dangers of unprotected RAS, enhancing relapse, and so does problem-focused coping, allowing unprotected sex, but with monogamous lovers. It can be argued that emotion-focused coping eventuates in related behaviors only to be expected; that is, we are "stacking the deck" to find a relationship between attitude and behavior. But it is important to observe (in Table 1) that a number of different cognitive domains were not related to corresponding behaviors, for example, coping with AIDS, beliefs regarding control, skill in dealing with partners, emotion-focused coping with abstinence, and the like. In addition, negative life events, for the most part, are associated with lapse, a not surprising relationship. Men who find ascertaining health status of potential partners awkward were more likely to maintain safer RAS behaviors. In the case of IAS, the constructs of coping ability, life events, mental health, and appraisal of stress were associated with maintenance, but the relationships between individual variables composing the five constructs and our dependent variables were not remarkable. This, perhaps, was partly because in RAS the behavior of the partner is more difficult to control than in IAS and because of the larger risk of AIDS in the case of RAS. The unique variables supporting the constructs may, if results are replicated with larger numbers, furnish suggestions for preventive intervention.

Although our investigation was unique and useful in following a sizable number of men over a long (30-month) period and in gathering psychosocial data to study a large number of explanatory factors, several flaws in our design are present and need to be avoided in future inquiries. We have no estimation of the degree of representativeness of our panel and no suggestions for assessing this. Of course, even the closer-to-universal ascertainment of cases and investigation of contacts possible with legally reportable sexually transmitted diseases still does not define the universe of such cases, but the potential for generalization of our findings is unknown.

In addition, we could not be certain of our study group's behavior in the time intervals between our contacts at the end of each 6-month period. What actually occurred during those intervals was only reported, not directly observed. Moreover, although we attempted to minimize errors of measurement through tests of reliability, such tests were not always available, and the possibility of errors in measurement of components of our constructs is large. Possible unreliability of change scores and autocorrelation among error terms added potential analytic complications. ${ }^{47}$ The fact that we made many assessments of relationships, of course, ensures that some, though statistically significant, will be misleading.

Another problem is that our samples of men engaging in receptive and insertive sex were overlapping. Thus, some men only engaged in insertive, and others in receptive, but a substantial number engaged in both types of behavior. Behavior in one situation may influence that in the other. The extent to which this complicates the analysis is unknown. Again, although we had a sizable panel of men to follow, it is clear that our numbers were 
too small to carry out many of the analyses we wished. Our study should be replicated with much greater numbers.

Perhaps the most serious caveat to consider in evaluating these findings inheres in the fact that the data were gathered in the period 1984 to 1988 and that changes in the situation with regard to AIDS in this country have occurred since that time. Nevertheless, we feel that even a tardy examination of data gathered in this research is useful in shedding light on the kinds of constructs that influence maintenance of preventive health behavior and relapse from it. These data remain important in furthering our understanding of the prevention of AIDS itself, but the constructs themselves perhaps have been shown to be important and to have implications for other preventive behaviors as well.

\section{Implications for Practice}

This research suggests that public health approaches to programs for changing behaviors in an AIDS-preventive direction could, with profit, build on the notion that psychological and social states are associated with such behaviors. Although negative life events and, to a degree, mental health are difficult to manipulate, coping response and certain personal factors can be improved through behavior change intervention. ${ }^{48,24,25}$ The beliefs that one is too lucky to get AIDS or that the chance of getting AIDS increases enjoyment or that a cure is imminent or that research by heterosexual investigators is biased may be addressed by cognitive and behaviorally oriented change efforts. The same is true for those who avoid thinking about AIDS or who feel they would have to stop all sex if they had to use condoms or who relapse in response to negative life events.

Treatment modalities for individual or small groups, such as role-playing to build sexual assertiveness, condom use, and sexual communication and problem-solving skills among men who cannot say no, could be useful. The same is true for those who have difficulty asking a potential lover about his disease history. The use of opinion leaders to encourage AIDS-preventive behavior is a community-level intervention requiring further application and evaluation. ${ }^{48,49}$ For a disease that is so costly in suffering as well as dollars, such investments are warranted.

\section{References}

1. Centers for Disease Control and Prevention: First 500,000 AIDS cases-United States, 1995. MMWR Morbid Mortal Wkly Rep 44(46):849-853, 1995.

2. Stall RD, Coates TJ, Hoff C: Behavioral risk reduction for HIV infection among gay and bisexual men: A review of results from the United States. Am Psychol 43:859-864, 1988.

3. Coates TJ: Strategies for modifying sexual behavior for primary and secondary prevention of HIV disease. J Consult Clin Psychol 58(1):57-59, 1990.

4. Schecter MT, Craib KJP, Willoughby B, Douglas B, McLeof WA, Maynard M, Constance P, O'Shaughnessy M: Patterns of sexual behavior and condom use in a cohort of homosexual men. Am J Public Health 78:1535-1538, 1988.

5. Joseph JG: Psychosocial Functioning in Gay Men. Unpublished manuscript, University of Michigan, Ann Arbor, 1980. 
6. Valdisseri RO, Lyter D, Callahan C, Leviton LC, Rinaldo CR: Condom Use in a Cohort of Gay and Bisexual Men. Paper presented to the 2nd Annual International Conference on AIDS, Washington, DC, July, 1987.

7. Valdisseri RO, Lyter D, Leviton LC, Callahan CM, Kingsley LA, Rinaldo CR: Variables influencing condom use in a cohort of gay and bisexual men. Am J Public Health 78:462-467, 1988.

8. Rodes A, Wang J, Blanch G, Tort X, Casabona J: Transverse study on sex behavior associated with HIV transmission among homosexual men in Catalonia (Spanish). Graceta Sanitaria 11(1):16-23, 1997.

9. Wang J, Rodes A, Blanch C, Casabona J: HIV testing history among gay/bisexual men recruited in Barcelona: Evidence of high levels of risk behavior among self-reported HIV + men. Soc Sci Med 44(4): 469-477, 1997.

10. Ekstrand M, Coates TJ: Maintenance of safer sexual behaviors and predictors of risky sex: The San Francisco men's health study. Am J Public Health 80(8):973-977, 1990.

11. Joseph JG, Kessler RC, Wortman C, Kirscht JP, Tal M, Caumartin S, Elshleman S, Eller M: Are There Psychological Costs Associated With Changes in Behavior to Reduce AIDS Risk? Unpublished manuscript, University of Michigan, Ann Arbor, 1990.

12. MacHale E, Newell J: Sexual behaviour and sex education in Irish school-going teenagers. Int J STD AIDS 8(3):196-200, 1997.

13. Stall R, Ekstrand M, Pollack L, McKusick L, Coates TJ: Relapse From Safer Sex: The Next Challenge From AIDS Prevention Efforts. Unpublished manuscript, University of California, San Francisco, 1989.

14. Adib M: Prevalence of Safe, Sexual Practices in a Cohort of Homosexual Men: A Two-Year Follow-Up From the Multicenter AIDS Cohort Study in Chicago. Unpublished manuscript, University of Michigan, Ann Arbor, 1990.

15. Adib M, Joseph JG, Tal M, Kirscht JP: Change in Condom Use in a Cohort of Homosexual Men at Risk of HIV Infection. Unpublished manuscript, University of Michigan, Ann Arbor, 1989.

16. St. Lawrence J, Hood HV, Brasfield TL, Kelly JA: Patterns and Predictors of Risk Knowledge and Risk Behavior Across High and Low Prevalence Cities. Paper presented to the Fourth International Conference on AIDS, Stockholm, Sweden, July, 1988.

17. Adib SM, Joseph JG, Ostrow DG, Tal M, Schwartz SA: Relapse in sexual behavior among homosexual men: A 2-year follow-up from the Chicago MACS/CCS. AIDS 5(6):757-760, 1991.

18. Osmond DH, Page K, Wiley J, Garrett K, Sheppard HW, Moss AR, Schrager L, Winkelstein W: HIV infection in homosexual and bisexual men 18 to 29 years of age: The San Francisco Young Men's Health Study. Am J Public Health 84(12):1933-1937, 1994.

19. Kelly JA, St. Lawrence JS, Brasfield TL: Predictors of vulnerability to AIDS risk behavior relapse. J Consult Clin Psychol 59:163-166, 1991.

20. Centers for Disease Control and Prevention: Patterns of sexual behavior change among homosexual/bisexual men-Selected U.S. sites, 1987-1990. MMWR Morbid Mortal Wkly Rep 40(46):792-794, 1991.

21. Prochaska JO, DiClemente CC: Self-change processes, self-efficacy and decisional balance across five stages of smoking cessation. Adv Cancer Control: Epidemiol Res 12:131-140, 1984.

22. Cohen S, Lichtenstein E, Prochaska JO, Rossi JS, Gritz ER, Carr CR, Orleans CT, Schoenbach VJ, Biener L, Abrams D, DiClemente C, Curry S, Marlatt GA, Cummings M, Emant C, Giovino G, Ossip-Klein DJ: Debunking myths about self-quitting. Evidence from 10 prospective studies of persons who attempt to quit smoking by themselves. Am Psychol 44(11):1355-1365, 1989.

23. Swan G, Denk C: Dynamic models for the maintenance of smoking cessation: Event history analysis of late relapse. J Behav Med 10(6):527-554, 1987. 
24. St. Lawrence J, Eldridge GD, Shelby MC, Little CE, Brasfield TL, O'Bannon RE III: HIV risk reduction for incarcerated women: A comparison of brief interventions based on two theoretical models. J Consult Clin Psychol 65(3):504-509, 1997.

25. Boyer CB, Barrett DC, Peterman TA, Bolan G: Sexually transmitted disease (STD) and HIV risk in heterosexual adults attending a public STD clinic: Evaluation of a randomized controlled behavioral risk-reduction intervention trial. AIDS 11(3):359-367, 1997.

26. Rewnicki R, Forgays DG: Recidivism and self-cure of smoking and obesity: An attempt to replicate. Am Psychol (January):97-110, 1987.

27. Pinkerton SD, Abramson PR: Effectiveness of condoms in preventing HIV transmission. Soc Sci Med 44(9):1303-1312, 1997.

28. Gochman D: Personal and social determinants of health behavior: An integration, in Gochman D (ed.): Handbook of Health Behavior Research. I: Personal and Social Determinants. New York, Plenum, 1997, pp. 381-400.

29. Fisher WA, Fisher JD, Rye BJ: Understanding and promoting AIDS-preventive behavior: Insights from the theory of reasoned action. Health Psychol 14(3):255-264, 1995.

30. Kim N, Standon B, Li X, Dickersin K, Galbraith J: Effectiveness of the 40 adolescent AIDS-risk reduction interventions: A quantitative review. J Adolesc Health 20(3):204-215, 1997.

31. Nyamathi A, Stein JA, Brecht ML: Psychosocial predictors of AIDS risk behavior in homeless and drug addicted women of color. Health Psychol 14(3):265-273, 1995.

32. Abel E, Miller I: Sexual risk behaviors among rural women of childbearing age. J Holistic Nurs 15(3):282-302, 1997.

33. Vincke J, Bolton R, Miller M: Younger versus older gay men: Risks, pleasures and dangers of anal sex. AIDS Care 9(2):217-225 1997.

34. Marlatt GA, Gordon JR: Relapse Prevention: Maintenance Strategies in the Treatment of Addictive Behaviors. New York, Guilford, 1985.

35. Lichtenstein E, Baer JS: Patterns of relapse and slip episodes. Health Psychol 5(suppl. 1):88-90, 1986.

36. Cronkite R, Moos R: Determinants of post-treatment functioning of alcoholic patients: A conceptual framework. J Consult Clin Psychol 48:305-315, 1980.

37. Shiffman S: Coping with temptations to smoke. J Consult Clin Psychol 52(2):261-267, 1984.

38. Gillespie CC: Women's HIV risk reduction efforts and traditional models of health behavior: A review and critique. Women Health 3(1):1-30, 1997.

39. Catania JA, Kegeles SM, Coates TJ: Towards an understanding of risk behavior: An AIDS Risk Reduction Model (ARRM). Health Educ Q 17(1):53-72, 1990.

40. Lazarus RS, Folkman S: The Coping Process: An Alternative to Traditional Formulations: Stress, Appraisal, and Coping. New York, Springer, 1984.

41. Joseph JG, Montgomery SB, Emmons C, Kessler RC, Ostrow DG, Wortman CB, O'Brien K, Eller M, Eshleman S: Magnitude and determinants of behavioral risk reduction: Longitudinal analysis of a cohort at risk for AIDS. Psychol Health 1:73-96, 1982.

42. Joseph JG, Adib M, Koopman JS, Ostrow DG: Behavioral change in longitudinal studies: Adoption of condom use by homosexual/bisexual men. Am J Public Health 80(12):1513-1514, 1990.

43. Joseph JG, Remmons C, Kessler RC, Wortman CB, O’Brien K, Hecke WT, Schafer C: Coping with the threat of AIDS: An approach to psychosocial assessment. Am Psychol 39:1297-1302, 1984.

44. Graham RP: Stress and Coping in Longitudinal Patterns of Relapse From Preventive Health Behaviors. PhD dissertation, University of Michigan, Ann Arbor, 1991.

45. Madalla GS: Limited-Dependent and Qualitative Variables in Econometrics. Cambridge, England, Cambridge University Press, 1983.

46. Fomby TB, Hill RC, Johnson SR:Advanced Econometric Methods. New York, Springer-Verlag, 1984. 
47. Kessler RC, Greenberg DF: Linear Panel Analysis: Models of Quantitative Change. New York, Academic Press, 1981.

48. Zimmerman MA, Ramirez-Valles J, Suarez E, de la Rosa G, Castro MA: An HIV/AIDS prevention project of Mexican homosexual men: An empowerment approach. Health Educ Behav 24(2):177-190, 1997.

49. Kelly JA: Sexually transmitted disease prevention approaches that work. Interventions to reduce risk behavior among individuals, groups, and communities. Sex Transm Dis 1(2, suppl.):S73S75, 1994. 